\title{
Middle school pre-service mathematics teachers' guidance for sixth grade students in problem solving process
}

\author{
Tangül Kabael ${ }^{1}$ and Betül Yayan ${ }^{2}$ \\ ${ }^{1}$ Elementary Mathematics Education, Anadolu University, Eskişehir , Turkey \\ 2,* Elementary Mathematics Education, Anadolu University, Eskişehir , Turkey \\ For correspondence: tuygur@anadolu.edu.tr
}

\begin{abstract}
The mathematics of the middle school has an important place in developing of algebraic thinking. Middle grades correspond to transition from arithmetic to algebra. According to Thompson and Smith (2007), quantitative reasoning provides a smooth transition from arithmetic reasoning to algebraic reasoning as a glue. Sixth grade and verbal problems are important in developing quantitative reasoning. On the other hand, As Harel (2008) emphasized, the important thing in problem solving is the ways of thinking rather than answering the problems correctly in school mathematics. Therefore, developing thinking ways of students is one of the responsibilities of mathematics teachers. This responsibility can get more difficult for pre-algebra students like sixth grade students. In this study, it was aimed to investigate pre-service middle school mathematics teachers' guidance for sixth grade students in problem solving process. This is a qualitatively designed study in which the data was collected through 10 pre-services teachers' clinical interviews with sixth grade middle school students. Data was analysed qualitatively by using content analysis technique. It was found that pre-service middle school mathematics teachers focused on students' getting the result rather than guiding their thinking ways. The abstract should be typed here (maximum 250 words).
\end{abstract}

Keywords: Problem solving, guidance of mathematics teachers, developing problem solving.

\section{Introduction}

Problem solving is one of the basic skills in mathematics education. Altun (2000) identified problem solving as knowing what to be done in unknown situations. Problem solving provides both development of students' cognitive abilities and simplicity to deal with difficulties they come across in their daily lives. At the same time, a student who has more developed problem solving skills uses mathematical knowledge better than the student who has less developed problem solving skills and also, this student is able to switch among her/his mathematical knowledge (Altun, 2008). According to Day and Jones (1997) as the students live systematic and meaningful problem solving experiences, mathematical thinking skills will improve and problem solving will be the most important component of the mathematical thinking. Researches on problem solving in which mathematics educators strongly emphasize begin with studies of Polya and the published book of Polya named as "How to solve it". In his book, Polya (1945) emphasizes that the first thing that mathematics teachers should make is to develop problem solving skills of the students. After Polya's studies on problem solving, problem solving becomes a studying area on which mathematics educators put emphasize. On the other hand, in some recently conducted studies it is emphasized that mathematics educators should reconsider this studying area on which they have been studying more than half of a century. For instance, English, Lyn, Lesh, Richard, Fennewald and Thomas (2008) examined the problem solving literature and claimed that models that were accepted by the mathematics educators isolated problem solving and there was no efficient improvement in the area of problem solving. De Corte (2004), indicated that nowadays the purpose of learning mathematics is to gain mathematical inclination to the learner rather than learning isolated mathematical concepts and acquiring mathematical skills. Harel (2001) indicates that problem solving is not only purpose of the school mathematics but also the meaning of learning mathematics. Harel (2007) emphasizes that problem solving approaches are not taken notice of or paid attention since the criteria of success in school 
mathematics problem solving is to answer problem correctly. On the other hand, when the process of problem solving is investigated, it is seen that the only criterion of success in problem solving is to answer the problem correctly and problem solving strategies in the learning environment and students' mental structures in the problem solving process are not considered (Harel, 2007).

In other respects, teachers are playing an important role in developing students' mathematical thinking and specifically problem solving skills. Some studies display that mathematics teachers focus on students' reaching to the solution and they ignore developing problem solving skills of the students (e.g. Harel \& Lim, 2004).

In this sense, guidance of mathematics teachers to develop their students' mathematical skills and specifically problem solving skills in the problem solving process becomes important. In the present study it was aimed to investigate middle school pre-service mathematics teachers' guidance for sixth grade students in the problem solving process.

\section{Methodology}

This is a qualitatively designed study in which the data was collected through 10 middle school preservices mathematics teachers' clinical interviews with sixth grade middle school students. Data was analyzed qualitatively by using content analysis technique.

\section{Results}

When the clinical interview processes of the pre-service teachers were investigated, it was observed that eight teachers out of ten teachers got students to focus on the solution of the problem rather than emphasizing the processes of understanding the problem, designing the solution plan and evaluation. Six pre-service teachers got students to read the problem and guided them to make operation without stressing the relationships between quantities and relations among quantities. On the other hand, two pre-service teachers left students by themselves and they did not make any questioning or guidance to reveal their mental structure and thinking ways. These pre-service teachers who did not emphasize the understanding process and who quickly guided students to make operations, suggested students to try a different way when the students selected inappropriate ways to solve the problem. Three of these pre-service teachers tried to guide students to use the mathematical representation giving the relationships rather than guiding students to understand relationships in the problem context. It was seen that students had difficulty with representing the relationships that they did not perceive and they had difficulty in this situation. It came up that students generally preferred using numbers and operations meaninglessly and uncomprehendingly in the interviews carried out without getting students to question quantities and relationships related to quantities. Only two of the pre-service teachers got students to question quantities and relationships among quantities in the process of understanding problem and they asked students to transform the relationships they understood verbally step by step into mathematical expressions. It was seen that the students of pre-service teachers who made this guidance were successful in using quantitative reasoning skills and it was thought that guiding styles of the pre-service teachers might be effective in this success. On the other hand in the process of evaluating the problem it was seen that four of the pre-service teachers did not guide students related to the problem or did not ask any question to the students and it came up that the students of these pre-service teachers checked the rightness of the solution by themselves without being guided. The other five of the pre-service teachers guided students for different solution strategies related to the problem in the process of evaluating problem and one pre-service teacher asked a question related to how to verify the solution student carried out. It was seen that two preservice teachers who guided students considering quantities and quantitative relationships got students to question their strategies they used in solution process and their beliefs related to the problem in the process of evaluating problem.

\section{Discussion and Conclusion}

The findings of this research revealed that pre-service mathematics teachers generally guided sixth grade students result-oriented rather than guiding them in thinking ways in the problem solving 
process. That the pre-service teachers guided middle school students to make operations rather than guiding them to question on the processes of understanding and evaluating problem may be the reason for that the students did not make sense the quantities and the relationships among quantitates in the problem. A teaching focusing on calculations and operations and is lack of with respect to quantitative meanings does not help in solving verbal problems as well as does not support developing students' strong problem solving skills and knowledge structures (Moore, 2010). On the other hand, Sowder (1988) characterized the learning environment focusing on numbers and operations rather than focusing on quantities and relationships among quantities in problem solving process as unfounded and useless discussion. However, the researches in literature have shown that teachers focus only procedural operations in problem solving and they ignore students' mental needs and thinking ways while they are teaching (e.g. Harel \& Lim, 2004). Therefore, courses ensuring that pre-service teachers are aware of which questions can be characterized as problems as well as courses in which pre-service teachers see and investigate different problem situations, and search possible solution approaches and strategies for a problem should be offered in mathematics teacher education programs (Lopez-Real \& Man-Sang Lee, 2006).

Problem solving has an important place in transition from arithmetic to algebra. The aims should be focusing on students' thinking ways and developing students' different thinking ways such as arithmetical and quantitative reasoning in the discussions related to problem solving in the prealgebra period (Smith \& Thompson, 2007). For instance, quantitative reasoning causing focusing on quantity and relationships among quantities provides students to structure algebra meaningfully and to solve problems productively (ibid). This study displayed that students of pre-service teachers who made quantitative reasoning-oriented questioning solve the problem simply. On the other hand, most of the students of pre-service teacher who did not get students to question quantities and relationships among quantities in the process of understanding problem had difficulty with solving problem. The most important reason for having difficulty with solving problems is that students engage with arithmetical operations rather than constructing appropriate mental models related to problem situation firstly (Mayer, Lewis, \& Hegarthy, 1992). Consequently, the basic aim of the teachers should be teaching students to think problem situations in learning environments (Mayer et al., 1992; Nathan \& Young, 1990). Solving problem situations those are rich with respect to quantitative relationships in learning environments does not mean developing students' problem solving skills and thinking ways, because students generally focus on operations and numbers in the problem situations. Students' constructing and relating quantities in the problem situations are only possible by guidance and questioning of teachers (Ellis, 2011). For this reason, while teachers are solving verbal problems, engaging students' reasoning structures and intending to develop an understanding based on quantities and relationships among quantities will prepare students better to solve verbal problems (Moore, 2010). For all these reasons, pre-service teachers should focus on thinking ways in problem solving process and they should question intended to develop the thinking ways.

\section{References}

Altun, M. (2000). İlköğretimde problem çözme öğretimi. Milli Eğitim Dergisi, 147, 27-33.

Altun, M. (2008). İlköğretim ikinci kademe (6, 7 ve 8. sinıflarda) matematik öğretimi. Alfa Yayınları, Bursa.

Day, R., \& Jones, G. A. (1997). Building bridges to algebraic thinking. Mathematics Teaching in the Middle Schools, 2(4), 208 213.

De Corte, E. (2004). Mainstreams and perspectives in research on learning (mathematics) from instruction. Applied psychology, 53(2), 279-310.

Ellis, A. B. (2011). Algebra in the middle school: Developing functional relationships through quantitative reasoning. In J. Cai \& E. Knuth (Eds.), Early algebraization: A global dialogue from multiple perspectives (pp. 215-238). Heidelberg, Germany: Springer.

English, L. D., Lesh, R., \& Fennewald, T. (2008). Future directions and perspectives for problem solving research and curriculum development. In In M. Santillan (Ed.), Proceedings of the 11th International Congress on Mathematical Education (pp. 6-13), Monterrey, Mexico.

Harel, G. (2001). Pupa's two complementary products: Taxonomy of students' existing proof schemes and DNR-based Instruction. International Newsletter on de Teaching and Learning of Mathematical Proof, 1-12.

Harel, G. (2007). The DNR System as a conceptual framework for curriculum development and instruction. In R. Lesh, J. Kaput \& E. Hamilton (Eds.), Foundations for the future in mathematics education (pp. 263-280). Mahwah, NJ: Erlbaum. 
Harel, G., \& Lim, K. H. (2004). Mathematics teachers' knowledge base: Preliminary results. In M.J. Hoines \& A.B. Fuglestad (Eds.), Proceedings of the 28th Conference of the International Group for the Psychology of Mathematics Education,(Vol. 3(3), pp. 25 - 32). Bergen, Norway.

Lopez-Real, F., \& Lee, A.M.S. (2006). Encouraging the use of technology in problem-solving: Some examples from an initial teacher education programme, The International Journal for Technology in Mathematics Education, 13(1), 23-30.

Mayer, R. E., Lewis, A. B., \& Hegarty, M. (1992). Mathematical misunderstandings: Qualitative reasoning about quantitative problems.Advances in psychology, 91, 137-153.

Moore, K. C. (2010). Relationships between quantitative reasoning and students' problem solving behaviors. Proceedings of the Fourteenth Annual Conference on Research in Undergraduate Mathematics Education (pp. 298-313). Portland, OR: Portland State University.

Nathan, M. J., \& Young, E. (1990). Thinking situationally: Results with an unintelligent tutor for word algebra problems. Computers in education, 425-430.

Pólya, G. (1945). How to solve it. Princeton. New Jersey: Princeton University.

Smith, J. P., \& Thompson, P. W. (2007). Quantitative reasoning and the development of algebraic reasoning. In J. J. Kaput, D. W. Carraher, \& M. L. Blanton (Eds.), Algebra in the early grades (pp. 95-132). New York: Lawrence Erlbaum

Sowder, L. (1988). Children's solutions of story problems. Journal of Mathematical Behavior, 7, 227-238. 